\title{
Los operadores jurídicos como impulsadores del conocimiento, la influencia, el bienestar social y la accesibilidad procesal de la mediación familiar en sede judicial
}

\author{
The legal operators as promoters of knowledge, influence, \\ social welfare and the procedural accessibility of family \\ mediation in the courts
}

\author{
Francisco Gorjon-Gomez ${ }^{1}$ \\ Rubinia Teresa Sandoval Salazar ${ }^{2}$
}

\begin{abstract}
Resumen
El presente articulo evidencia la necesidad de cambiar las estrategias de culturización en el uso de los MASC, proponiendo situar a la mediación en una política de bienestar social, con sustento en la felicidad y en la utilidad social. Destacamos la importancia de la mediación en los procesos judiciales familiares ya que genera una solución perene al conflicto, desde la perspectiva del interés de las partes y no desde el incumplimiento de la norma. Su implementación recae en los diversos operadores jurídicos del proceso lo que lo hace mas accesible y produce bienestar subjetivo, generando acciones positivas que a su ves se traducen en elementos que influyen en la sociedad para su implementación, entendiendo la mediación en sede judicial como el punto de partida idóneo para generar una cultura, ya que la norma lo prevé, empero, vinculando a todos los operadores jurídicos en el marco de una política social y no solo normativa.
\end{abstract}

\section{Palabras Clave}

Mediación familiar, Operadores jurídicos, Accesibilidad Procesal, Bienestar Social

\footnotetext{
${ }^{1}$ Doctor por la Universidad Complutense de Madrid, Miembro del Sistema Nacional de investigadores Nivel II, Profesor Investigador de Tiempo Completo de la Facultad de Derecho y Criminología de la UANL, México, Director Académico del Doctorado en Métodos Alternos de Solución de Conflictos de la Universidad Autónoma de Nuevo León, presidente de la Asociación Internacional de Doctores en Métodos Alternos de Solución de Conflictos ASID/MASC. ORCID ID: 0000-001-5296-6454: Email: fgorjon@ hotmail.com

2 Alumna del Programa Doctoral de Métodos Alternos de Solución de Conflictos de la Facultad de Derecho y Criminología de la Universidad Autónoma de Nuevo León en México, Maestría en Métodos Alternos para Solución de Controversias de la Facultad de Derecho y Criminología de la Universidad Autónoma de Nuevo León en México, Abogada Litigante en materia familiar. ORCID ID: 0000-0018970-6103 Email: ruby_rd@hotmail.com
} 


\begin{abstract}
This article demonstrates the need to change the strategies of acculturation in the use of alternative methods of conflicto resolution, proposing to place mediation in a social welfare policy, with sustenance in happiness and social utility. We emphasize thei mportance of mediation in family judicial processes as it generates a perennial solution to the conflict, from the perspective of the interest of the pates and not from the breach of the rule. It simplementation falls on the various legal operators of the process, which makes it more accessible and produces subjective well-being, generating positive actions that in turn translate into elements that influenc society for it simplementation, understanding the mediation in judicial offices as the point of ideal starting poin to generate culture, since the norm foresees it, however, linking all the legal operators in the frame of a social policy and not only normative.
\end{abstract}

\title{
Keywords
}

Family mediation, Legal Operators, Procedural Accessibility, Social Welfare

\section{Introducción}

Abordamos el tema desde dos perspectivas, la mediación como un elemento sustancial del bienestar y la mediación como proceso en la solución de conflictos familiares, en ambos casos la mediación es considerada la vía idónea para resolver los conflictos familiares, gestionándolos y transformándolos de forma intraprocesal o extraprocesal.

Planteamos que la mediación no ha evolucionado y permeado lo suficiente en la sociedad, que no hay una cultura al respecto, señalamos que no está en la genética social y ello se debe principalmente que su culturización se basa en políticas jurisdiccionales limitadas a un ámbito de influencia legal entendiendo a la mediación solo como instrumento legal y no como un instrumento de concertación social y de pacificación. Esto genera que aun que está implícita la mediación en la norma la sociedad la ignora y en consecuencia a los mediadores, esto aparejado a la desconfianza que existe en el proceso judicial.

Señalamos como punto toral de esta idea que la mediación produce felicidad con un alto grado de utilidad y se sustenta en la confianza al mediador y al procedimiento mismo, estos elementos son considerados valores intangibles de los MASC de gran impacto, de fácil entendimiento y mejor operatividad, equiparados al bienestar subjetivo que se presenta en nuestro circulo de convivencia primario, esto es, nuestras relaciones con la familia, el trabajo, los amigos, etc., por lo que elevar a la mediación a una política de 
bienestar social garantizara su éxito y ampliaría radicalmente su espectro de instrumentalización e influencia.

Destacamos igualmente como la normativa es proclive al desarrollo de los MASC, sin embargo, los operadores jurídicos entiéndase, abogados, jueces entre otros son omisos y como señalaremos adelante son inocuos al procedimiento de gestión y transformación del conflicto, evitan su aplicación y prefieren abordar la solución desde la perspectiva del incumplimiento de la norma y no desde los intereses de las partes, referenciamos esta situación conforme al procedimiento establecido en las leyes mexicanas con especial referencia a la del Estado de Nuevo León, ya que existen 26, sin embargo, asumen criterios homologados que se encuentran presentes en las principales convenciones internacionales y leyes modelos relacionadas con los MASC, concluyendo que la norma es proclive a la mediación pero los operadores jurídicos no, la mesa está servida para la mediación, sentemos a los abogados, a todos las demás profesiones pero principalmente a al sociedad, por lo que tendremos que replantear las estrategias y políticas de culturización, las actuales han sido de corto alcance y limitadas solo al proceso judicial.

\section{La mediación como generadora de Bienestar Social}

La mediación y los diversos métodos alternos de solución de conflictos (MASC) se han revitalizado con el paso del tiempo, motivado por las nuevas dinámicas sociales de interacción social, reconociendo el sistema su valía, generando con ello leyes específicas que los impulsan y elevándolos en algunos casos a categoría de derecho humano como sucede en México ${ }^{3}$, esto es, que ante la creciente demanda de procesos en los juzgados, así como también la interacción entre sectores sociales y la multidisciplinariedad de los diversos actores en los procesos judiciales, el papel que ellos juegan se han vuelto necesarios como tamiz social, entendiendo que ya no solo son considerados como un método alterno, sino como herramientas de paz. Sin embargo y reconociendo su status normativo y sus valores intangibles, la mediación debería ser utilizada, empero, no sucede y la sociedad la desconoce.

\footnotetext{
${ }^{3}$ V. articulo 17 de la Constitución Política de los Estados Unidos Mexicanos
} 
La razón de ello se debe principalmente a la postura inocua del abogado. Se ha discutido en sinnúmero de foros el porqué de tal postura, y algunas de las conclusiones ha sido la apatía, el desinterés, la desconfianza, la ignorancia, la falta de percepción de sus intangibles, etc. Todas las razones son conocidas y tiene un peso significativo, pero no nos hemos detenido a pensar porque se generan, situación que es grave ya que por antonomasia descansa en él, la culturización de la sociedad para el uso e implementación de los MASC.

Nuestra conclusión al respecto es que la vía utilizada es la incorrecta, la promoción y la culturización del uso de los MASC se centra en una política jurisdiccional, esto es, su encausamiento sigue las mismas dinámicas que el de las leyes, desde su creación, hasta su ejecución, entonces, si los procesos de creación de leyes y de enseñanza de las mismas es lento y sectorizado, entonces el resultado del proceso de culturización es igualmente lento y sectorizado, siguen la misma suerte, limitando entonces el conocimiento de los MASC y de su instrumentalización al mundo del abogado, significando que aún que las leyes se publican y son aplicables a todos, la mayoría de la sociedad las desconoce, aunado a la creciente desconfianza de la sociedad al sistema de procuración y de impartición de justicia, verbigracia, llegando la cifra negra alcanzar el 93.7\%, siendo solo un reflejo de la dinámica de la política normativista moderna, que produce un alto nivel de inseguridad.

Por ende, es necesario cambiar esta dinámica de culturización y cambiar la estrategia conforme otras dinámicas políticas e introducir otros elementos que la cambien e integre a la sociedad como el actor principal y no como un observador ignorante.

El elemento al cual hacemos alusión es el bienestar que se centra al igual que los MASC en el interés de las personas yen su felicidad. En consecuencia, la vía de culturización de los MASC se propone sustentarla en la dinámica del Bienestar Subjetivo, en el que el rol principal de su entendimiento y funcionalidad es la felicidad, ya que todas las personas buscan la felicidad, además de ser un concepto ampliamente conocido que se encuentra en la genética social, a diferencia de los preceptos legales que no están socializados.

A la letra Bisquerra ${ }^{4}$ señala que "la felicidad surge de una opción personal y no puede ser impuesta. Cada quien tiene la libertad de decidir sobre estas cuestiones", la felicidad

${ }^{4}$ BISQUERRA ALZINA, Rafael. Cuestiones sobre bienestar. Síntesis. Madrid, 2013. p. 15. 
continúa señalando el autor es "considerada un sinónimo del bienestar subjetivo porque crea un clima emocional positivo favorable, porque las emociones se contagian, son de fácil acceso y comprensión, cada individuo construye su bienestar personal desde su propia autonomía e interés".

Es la autonomía el pilar de los MASC, al igual que su respeto, sin ella son inoperativos, entonces, cambiemos de dinámica y subámonos a la dinámica del bienestar subjetivo y bajemos de la dinámica de las políticas normativas en donde jerarquicemos y privilegiemos los interés de las partes y su felicidad, con respeto absoluto al orden público y al estado de derecho, este ultimo ha liberado el uso de los MASC razón de más para considerar esto como una meta viable, pero la sociedad no lo sabe, ignora la mediación, desconoce su existencia y en consecuencia no sabe que los mediadores existimos.

$\mathrm{Al}$ respecto surgen tres incógnitas, que es el bienestar subjetivo y cuales son sus rasgos distintivos, como es una política pública basada en el bienestar subjetivo y como la vinculamosa los MASC.

Continuando con Bisquerra, afirma que el bienestar subjetivo "consiste en una

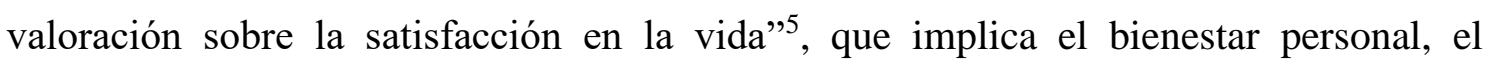
emocional y la felicidad, por lo que ante el conflicto y su existencia no se puede lograr, trastocando entonces el status quo del individuo, desestabilizándolo; interpretando a Redorta $^{6}$ podría decirse que el individuo vive en un constante malestar y no vive, sobrevive, entonces ante este hecho nos obliga a buscar el mecanismo idóneo para resolver el conflicto, es aquí en donde surgen los MASC, que lo gestionan y la transforman en razón del interés de las partes y su felicidad.

Para que ello pueda darse se requiere de la confianza en el mediador, que al igual que el bienestar subjetivo se convierte en el pilar central de su instrumentalización, "las personas que viven en un contexto de alta confianza tienen niveles más altos de bienestar, ya que el nivel de confianza de la comunidad produce efectos sobre las personas de seguridad"7.

Privilegiándose entonces a la satisfacción, a la calidad de vida, a las emociones y a la felicidad como los elementos centrales y rasgos distintivos de este proceso y en

${ }^{5}$ Ibid. p. 92.

${ }^{6}$ REDORTA, Josep. Como sobrevivir a la sociedad del malestar y el conflicto. Almuzara. España, 2018.

${ }^{7}$ BISQUERRA ALZINA, Rafael. Cuestiones sobre bienestar. Síntesis. Madrid, 2013. p. 71. 
consecuencia alineándolosal procedimiento de mediación que soluciona el conflicto y producen seguridad.

Ahora bien, como operacionalizamos esto en una política social, mientras que en las políticas normativas se privilegia a la norma y se aborda el conflicto como el incumplimiento de la norma, en la política del bienestar subjetivo se privilegia la felicidad y la mediación aborda el conflicto desde los intereses de las partes, gestionándolo y transformándolo produciendo bienestar, integrando activamente en esta ecuación a la confianza, al respecto Membiela ${ }^{8}$ señala que la confianza en sus diversas acepciones (particular, social, institucional) favorecen significativamente la felicidad y la satisfacción vital de los individuos, destacando que: "la confianza es un elemento relevante en si mismo, por el cual se aprecia la capacidad de confiar en los demás y también como variable instrumental que facilita la interacción social, la cooperación y la reciprocidad". Analizando lo anterior reconfirma nuestra postura ya que los MASC, en especial la mediación se sustenta en la confianza en el mediador, para su éxito y cumplimiento del acuerdo.

Aunado a lo anterior toda política publica se centra en generar bienestar y debe de reportar una utilidad social, siendo equiparada esta igualmente a la felicidad ${ }^{9}$, por lo que la felicidad es "un constructo subjetivo y no es unidimensional si no es un fenómeno complejo y multifacético" ${ }^{10}$ por lo que la idea de la utilidad es ad -hoc por su amplio espectro, entendiéndola como una satisfacción percibida asociada a la capacidad de las personas de elegir, a la calidad del resultado que produce y su intensidad, a su permanencia en el tiempo como una experiencia retrospectiva y al incremento de sensaciones positivas, “...de procesos institucionalizados que interiorizan e incrementan sensaciones positivas..."11 que aseguran el cumplimiento perene del acuerdo, por lo que mientras la política normativa se centra en el cumplimiento de la norma, la política del bienestar se centra la utilidad social, en consecuencia en la felicidad de las personas.

Ahora bien, como vinculamos a los MASC al bienestar subjetivo, a través del resultado del procedimiento de mediación, ya que el acuerdo de mediación produce felicidad y la felicidad es uno de sus principales intangibles porque entendemos que estar feliz es

\footnotetext{
${ }^{8}$ MEMBIELA POLLÁN, Matías. Teoría del capital social. Camiño Do Faro. España, 2016. p. 214. ${ }^{9}$ Ibid. p. 178.

${ }^{10}$ Íbid.

${ }^{11}$ Íbid. p. 180.
} 
"Sentir gozo, estar satisfecho, y vivir un estado de bienestar, combinado con la sensación de que nuestra vida en buena, tiene sentido y vale la pena"12 este concepto a su vez tiene dos componentes el afectivo y el cognitivo. El afectivo tiene que ver con la frecuencia con que sentimos emociones positivas y negativas. El componente cognitivo es la satisfacción de la vida, la manera que evaluamos nuestra propia satisfacción con las diferentes áreas de nuestra existencia.

Los estudiosos de la felicidad ${ }^{13}$ proponen una fórmula para explicar los factores que constituyen la felicidadF $=\mathrm{PF}+\mathrm{C}+\mathrm{V}$. La felicidad $(F)$ está compuesta por un punto fijo $(P F)$ más las circunstancias de la vida $(C)$ más nuestra voluntad o volición (V). En un entorno eminentemente de utilidad social que procura el bienestar subjetivo que impacta en la calidad de vida vinculada a los componentes sociales de la familia, el trabajo, la salud, los amigos etc.

Afirmamos entonces que (PF) será la relación existente entre las partes que generan obligaciones entre ellas, esto es cualquier tipo de contrato o vinculo relacional; (C) está representada por las circunstancias en el que el conflicto surge entre las partes y altera su bienestar y por último la (V) será la voluntad de las partes que las mueve para resolver satisfactoriamente el conflicto ${ }^{14}$.

Concluyendo, el abogado debe de promover la mediación desde la perspectiva del bienestar subjetivo, surgiendo entonces la gran oportunidad en la mediación intrajudicial, en la mediación en sede judicial como vía idónea para transformar a las partes y al sistema judicial y de procuración de justicia y a todos sus integrantes, desde su interior, desde sus propios procesos que habilitan a la "mediación" convirtiéndose entonces el abogado en un agente de cambio social, al tener a su alcance a todos los actores sociales en un mismo lugar yen un mismo momento, en un estadio proclive al cambio.

\section{La mediación familiar en sede judicial}

\footnotetext{
${ }^{12}$ TAPIA VARGAS, A., \& Et.al. Psicologia positiva. Definición. Los pilares de la felicidad. Beneficios de las emociones positivas. Las personas sanas. Trillas. México, 2012.

${ }^{13}$ Íbid.

${ }^{14}$ GORJÓN GÓMEZ, Francisco Javier. Mediación su valor intangible y efectos operativos. Una visión integradora de los MASC. Tirant Lo Blanch. México, 2017.
} 
Los juicios familiaresson impulsados por las partes en conflicto por medio de los abogados litigantes, quienes actúan para exigir un derecho o defenderse,brindando una asesoría jurídica eficiente, con el fin de construir una estrategia legal con el objeto de iniciar alguna acción por medio del proceso judicial, así mismolos jueces tienen como función principal la administración de la justicia mediante la aplicación efectiva de las normas judiciales, con la colaboración de los operadores jurídicos, en consecuenciael sistema judicial debería garantizar el efectivo acceso a la justicia.

La mediación familiar es "como un sistema cooperativo de gestión y resolución de conflictos entre los miembros de una familia"15. La mediación familiarbusca tener un rol más activo dentro de los procesos judiciales y esto se puede lograr con la ayuda de los abogados litigantes mediante un efectivo asesoramiento sobre la justica alternativa y divulgando las nuevas formas de resolver los conflictos de índole familiar de una forma integral en especial a través de la mediación, con apoyo de los jueces familiares en donde faciliten el acceso a la justicia alterna dentro de los juicios familiares.

La mediación familiar en sede judicial o intraprocesal aplica cuando se ha presentado una demanda y esta ha sido admitida y posteriormente se emplaza a la contraparte para iniciar el reclamo de alguna acción u omisión legalpor medio de un proceso judicial y durante este proceso judicial a las partes por iniciativa propia o por sugerencia de sus respectivos abogados o por la exhortación realizada por los jueces familiar las partes acceden a suspender el proceso judicial, para derivar la controversia a una unidad de mediación o acudir a un instituto de mecanismo alternativos para la solución de controversias como es en el caso mexicano ${ }^{16}$, a fin de tratar de llegar a un convenio de mediación, y acudir ante la autoridad judicial para homologar el convenio de mediación. La mediación familiarse encuentra reguladapor la Ley de Mecanismos Alternativos para la Solución de Controversias para el Estado de Nuevo León (LMASCNL), con relación al Código de Procedimientos Civiles vigente en el estado de Nuevo León, ambos ordenamientos jurídicos regula la posibilidad de acudir a la justicia alterna dentro de los juicios familiares orales y tradicionales, el cual se menciona que los jueces deben

\footnotetext{
${ }^{15}$ GARCÍA VILLALUENGA, Leticia."La mediación familiar: una aproximación normativa”. Revista del Instituto de Ciencias Jurídicas de Puebla A.C.2007. núm. 20.p.9.

${ }^{16}$ Existen en México 26 leyes estatales que regulan la mediación. V. Vgr. Ley de Mecanismos alternativos de solución de controversias del Estado de Nuevo León.
} 
proponer a las partes que acudan a un mecanismos alternativo para resolver su conflicto legal por medio de un convenio de mediación.

Esto es una tendencia nacional y considerado un derecho humano al estar determinado en la Constitución Política de los Estados Unidos Mexicanos en su artículo 17, quinto párrafo, en este precepto garantiza el acceso a los tribunales previamente establecidos y contempla también la posibilidad de que los conflictos familiares de índole legal puedan resolverse por medio de un MASC, brindándole a la sociedad un derecho fundamental para acceder de forma efectiva a los procesos alternativos al momento de iniciar una contienda judicial.

La derivación de controversia es aquella derivación de una autoridad judicial o administrativa, con relación a una causa formalmente establecida,esto se refiere a que la derivación de una controversia se da cuando se inicia un proceso judicial y el juez exhorta a las partes a someter su conflicto legal a un MASC.

La forma de llevarse a cabo la derivación de la controversia se encuentra regulado en la LMASCNLen el caso de que se haya iniciado el procedimiento por la vía jurisdiccional, en el acuerdo de radicación, el Juez notificará a las partes el derecho que tienen de optar por el procedimiento alternativo, señalándoles un plazo de 5 días hábiles para que manifiesten lo que a su derecho convenga, siendo necesario que, si optan por éste, se exprese por escrito la voluntad de todas las partes, la autoridad judicial tiene la obligación de hacer saber a las partes que pueden derivar su controversia a un procedimiento alternativo.

El código de Procedimientos Civiles en el estado de Nuevo León establece que las partes tienen el derecho de utilizar otros medios alternos tales como la amigable composición o la mediación y/o la conciliación. Dicha regulación no resulta ser suficiente para que la sociedad pueda acceder de forma fácil y sencilla a elegir algún MASC, este precepto aplica en los juicios familiares en el auto de radicación la autoridad judicial notifica a las partes el derecho que tienen para acudir a uno de ellos, es especial la mediación.

Esta regulación procesal no facilita el acceso a la justicia alterna, ya que no menciona la forma en que debe llevarse a cabo la fase de la información y en consecuencia no es suficiente esta regulación para que la sociedad con apoyo de los operadores jurídicos puedanimpulsar la mediación familiar en la sede judicial,debido a que la 
informaciónbrindadasobre los MASCdurante el proceso judicial es escasa sobre todo en lo relacionado al desarrollo del proceso de mediación, dejando a la sociedad con un escaso conocimiento de lo que son los mecanismos alternativos.

La regulación procesal dentro de los juicios orales en materia familiar se encuentra en el Código de Procedimientos Civiles en el Estado de Nuevo León el cual establece que el Juez les propondrá someterse a un MASC, y si están de acuerdo con esta vía, se procederá conforme a la LMASCNL, estos preceptos legales solo indican que el juez familiar de forma directa debe invitar a las partes antes de iniciar la audiencia preliminar a que acudan al Instituto de Mecanismos Alternativos para la Solución de Controversias en el estado de Nuevo León con el fin de resolver su conflicto por medio de la mediación familiar.

El código civil adjetivo refiere como debe implementarse la mediación familiar dentro de los juicios familiares, así como en qué momento debe realizarse la invitación sobre los mecanismos alternativos y quien debe exhortar a las partes para que resuelvan sus conflictos por medio de algún mecanismo alternativo, la legislación aquí citada refiere que el juez debe proponerlos, que debe hacerlo saber en el auto de radicación a las partes en conflicto, y en el caso de los juicios orales la invitación la realiza el juez de forma directa antes de iniciar la audiencia preliminar.

La invitación a los MASCrealizada por los jueces familiares dentro de los procesos judiciales se limita en manifestar que existenpara la solución de controversias y que estos mecanismo alternos ayudan a las partes a resolver sus conflictos con un convenio de mediación, sin embrago, la legislación adjetiva no regula como debe llevarse a cabola invitación para su instrumentalización, ni establece como deben colaborar los operadores jurídicos para su operación que forman parte activa dentro de los juicios familiares y poder participar de forma colaborativa para garantizar el efectivo acceso a la justicia alterna.

\section{El conocimiento de la mediación por parte de los operadores jurídicos}

Los MASC trajeron consigo un cambio en la administración de la justicia tradicional y como todo cambio da como resultado que todos los que intervienen en los juicios están obligados a cambiar su praxis para permitir que el nuevo sistema logre sus objetivos, de nada sirve mejorar o cambiar un modelo de justicia si no es adoptado por todos los 
involucrados en el desarrollo de la aplicación de la justicia y obtener los beneficios en ámbito legal.

"La sociedad en general pose un escaso conocimiento de los Métodos Alternos de Solución de Controversias" ${ }^{17}$ Debido a esto los legisladores deberían con cooperación con los operadores jurídicos tener la obligación y el deber de divulgar la existencia y el funcionamiento de los MASC y en espacial la mediación por ser el método más proclive para gestionar el conflicto familiar para lograr su solución; en tanto que los abogados litigantes en materia familiar deben informar y asesorar de forma efectiva a sus clientes sobre la impartición de los MASC, generando en las partes un conocimiento integral de lo que es el procedimiento de mediación, es decir explicar de forma detallada los beneficios, las ventajas, como funciona, su procedimiento y deben de crear conciencia en sus clientes de la importancia de los beneficios en especial de su intangibles ${ }^{18}$.

En los juicios familiares durante el desarrollo del proceso judicial se sufre de una escasa información por parte de los jueces familiares, sobre el funcionamiento y los beneficios del proceso de mediación, debido a la forma en la que se realiza la invitación para derivar la controversia,los operadores jurídicos tienen una ética profesional mediante la cual desarrollan sus actividades profesionales ytienen la obligación y el deber deinformar sobre los mecanismos alternativos de lo contrario como menciona Pastrana Aguirre "Es entonces atribuible el fracaso, no a la mediación misma, sino a la falta de voluntad de las partes por cooperar en el proceso ganar-ganar"19. De ahí la importancia que juega el rol activo de los operadores jurídicos para impulsar los procesos de mediación dentro de los juicios familiares.

El conocimiento sobre los MASC generado por los operadores jurídicos hacia las partes trae consigo la posibilidad de que las partes manifiesten su voluntad para iniciar un proceso de mediación, y con ello poder que las partes puedan entender y comprender cada uno de los mecanismos alternativos que integran la justicia alterna y generar una confianza que permita cambiar la cultura jurídica de las partes al momento de someterse a un mecanismo alternativo.

\footnotetext{
${ }^{17}$ GORJÓN GÓMEZ, Francisco Javier. Métodos Alternos de Solución de Controversias. Continental. México,2007. p.19.

${ }^{18}$ GORJÓN GÓMEZ, Francisco Javier. Mediación su valor intangible y efectos operativos. Una visión integradora de los MASC. Tirant Lo Blanch. México, 2017.

${ }^{19}$ PASTRANA AGUIRRE, Laura Aida.La mediación en el sistema procesal acusatorio en México. Flores Editor y Distribuidor S.A. DE C.V. México D.F. 2009. p.72.
} 
Las partes, en la mayoría de los casos podrán acceder a un acuerdo de voluntades por medio de la mediación u otro MASC, si se logra un conocimiento efectivo sobre el proceso de la mediación familiar en sede judicial, ya que para acudir a un procedimiento de este tipo y llegar a un acuerdo de mediación, se debe tomar en cuenta que se busca el consentimiento de las partes el cual se define "como un acuerdo de voluntades que implica la existencia de un interés jurídico" ${ }^{20}$, la cual es uno de los elementos más importantes para empezar impulsar las mediaciones en sede judicial.

"Debemos trabajar en la voluntad de las partes para que los procesos de mediación empiecen a fortalecer el sistema judicial mediante convenios integradores que propician el bienestar familiar enmendando los lazos familiares" 21 y esto se logra rompiendo con la barrera de la voluntad de las partes aunado con la influencia positiva de los operadores jurídicos con la intención de solucionar las controversias de forma integral en base al respeto, brindando suficiente información por parte de los operadores jurídicos persuadiendo a las partes a que empiecen a tratar de resolver sus problemas por sí mismos, previamente bien asesorados empoderándolos para solucionar su contienda familiar.

Se requiere expertos en el área para impulsar lasderivaciones judicialesa la mediación familiar, y un "mediador competente que pueda mejorar el proceso de comunicación y negociación trabajando con las partes a efecto de enfocar el tema"22, que no permita que las mediaciones fracasen, se necesita que los operadores jurídicos concienticen a las partes de la importancia y la necesidad de acudir a un proceso de mediación familiar en la sede judicial.

El conocimiento sobre los MASC así como de sus beneficios e intangibles puedecambiar la percepción de la forma de resolver los conflictos legales, en donde los operadores jurídicos generen una conciencia jurídica en donde las partes entiendan y aprendan que los conflictos legales no necesariamente se resuelven litigando, esta conciencia jurídica es reconocer que existe un conflicto familiar y que por el bien de la familia, empezar avelar por el bienestar emocional, físico y mental de todos sus integrantes y recuperar los lazos familiares que fueron lastimados.

${ }^{20}$ GARCÍA TREVIÑO, Ricardo, Los Contratos Civiles y sus Generales. Mc Graw-Hill Interamericana Editores S.A. DE C.V., México D.F., 2002, p. 9.

${ }^{21}$ Ibid.

${ }^{22}$ PASTRANA AGUIRRE, Laura Aida, La mediación en el sistema procesal acusatorio en México. Flores Editor y Distribuidor S.A. DE C.V., México D.F., 2009, p.67. 
Los MASC en especial la mediación busca generar un cambio jurídico social, este requiere trabajar sobre la generación de una nueva cultura jurídica por parte de los operadores jurídicos y las partes inmersas en una contienda familiar en donde las emociones como el odios, el rencor, la depresión, la impotencia muchas de las veces no deja que la justicia alterna llega a sus vidas, las familias en contienda deben tener claro que no todos los conflictos familiares se gana litigando, que también existen otras forma alternas dentro del sistema judicial.

\section{Cultura jurídica del Ciudadano}

La cultura representa la forma de actuar de una determinada sociedad en una época determinada, es un conjunto de conocimientos que es trasmitido de generación en generación, cambiar una cultura de una sociedad se requiere de mucho tiempo y esfuerzo, ya que la cultura determina la forma de vivir la vida, de actuar frente a la sociedad y de la forma de ver y resolver los problemas cotidianos.

"El concepto cultura respecto al de cultura jurídica, no es ajeno, al insertarse a éste la palabra "jurídica" es de entenderse aplicable a las personas en cuya forma de vida se encuentra dentro del contexto del derecho o pertenecientes a las leyes o atañe o se ajusta a ellas"23. El derecho es un fenómeno cultural y dinámico, ya que es creado por el hombre en un tiempo y espacio determinado,el cual debe ir cambiando en razón a las necesidades de la sociedad, con el fin de procurar la paz social, la justicia, por lo cual la cultura jurídica determina la forma de actuar de la sociedad y de los operadores jurídicos dentro del sistema judicial.

Las sociedades están inmersas en constantes cambios jurídicosque consisten en reformas legales que deben adecuarse a las necesidades sociales, por lo cual los operadores jurídicos deben aplicar siempre su ética profesional, a fin de contribuir a la evolución de la aplicación de derecho en la impartición de la justicia alterna, y evitar obstáculos procesales que dilaten o restrinjan la solución de conflicto, lograr cambios jurídicos en beneficio de la sociedad.

\footnotetext{
${ }^{23}$ TORRES BUENROSTRO, Elizabeth.Cultura, Cultura Jurídica y Enseñanza del Derecho: factores Trascendentes de cambio social. Biblioteca jurídica virtual del Instituto de Investigaciones jurídicas de la UNAM, 2011.p.27.
} 
La cultura jurídica "no es el particular modo de entender el derecho como producto unívoco, sino por el contrario, es descubrir el conjunto de entendimientos sobre los que se basa" ${ }^{24}$, para lograr que las partes acepten los MASC los operadores jurídicos deben brindar información que permita cambiar las tradicionales formas de ver y administrar la justicia,por medio del efectivo asesoramiento sobre el proceso de mediación, de lo contrario la sociedad siempre estará atada a la vieja cultura jurídica de litigar.

Las nuevas formas de la justicia alterna vienen encaminadas a cambiar la cultura jurídica de las familias en disputa dentro del sistema judicial tradicional,busca concientizar a los miembros de las familias en conflictos dando a conocer que hay una nueva forma de resolver conflictos por medio deestos métodos en materia familiar en sede judicial, que ya existen considerados vías conciliadoras menos desgastantes, que van másallá de buscar una sentencia dictada por un juez, ahora las familias deben buscar de forma cooperativa una solución acorde a las necesidades familiares como un interés superior que rija el proceso, propiciando un cambio en la cultura jurídica en la forma de conducir sus conflictos legales con el apoyo de los operadores jurídicos.

"Los sistemas jurídicos del mundo se preocupan cada vez más por regular normativamente la corrección procesal de las partes, buena fe, moralidad/lealtad o probidad del debate y/o el abuso del/en el proceso" 25 por medio de los procesos judiciales se trata de tener un efectivo acceso a la justicia y mejorar la cultura jurídica por parte de la sociedad en conflicto legales familiares, en el cual se logre dar a conocer los diverso procesos mediante el cual permita ver la nueva manera de resolver los conflictos familiares.

"La conducta de las partes debe ajustarse a cánones de moralidad y buena fe, no sólo para que el debate se lleve a cabo respetando las reglas del juego, sino para que la conducta de las partes esté también en sintonía con las finalidades últimas del proceso" 26 . Las partes por medio de sus abogados litigantes deben proceder de buena fe al momento de acudir a una autoridad judicial respetando las formalidades procesales, buscando una justicia en su entorno familiar, los conflictos familiares en su mayoría

\footnotetext{
${ }^{24}$ Suprema Corte de Justicia de la Nación. Anuario de la Cultura Jurídica Mexicana. Suprema Corte de Justicia de la Nación, México, D.F. 2007, p. 16.

${ }^{25}$ GONZÁLEZ CARVAJAL, Jorge Isaac."Consideraciones generales sobre la buena fe procesal y el abuso procesal”. Revista Latinoamericana de Derecho Procesal 1, № 3, mayo, México, 2015. p. 18.

${ }^{26}$ Ibid. p. 24.
} 
traen cargas emocionales muy fuertes, esto les puede impedir actuar de forma objetiva dentro de un proceso judicial.

Los operadores jurídicos y el sistema judicial deben sensibilizar su actuar en los procesos judiciales y eliminar la cultura jurídica de litigio infinito a una cultura jurídica pacifica en donde las partes sean conscientes de sus acciones que se vea reflejado en una cultura jurídica en busca de soluciones y no de demostrar quien tiene la razón, por ello las familias en conflicto deben empezar a cambiar esa cultura jurídica del litigio y empezar a encaminar su pensar y sus acciones a buscar soluciones en base a las necesidades de la familia, fomentando por parte los abogados litigantes una cultura jurídica pacifica por medio del dialogo constructivo.

Las partes y los operadores jurídicos deben dejar el "proceso como método para atribuir razón a quien la tiene" ${ }^{27}$, el sistema judicial mexicano ya prevé un proceso alternativo que tiene como objetivo buscar soluciones pacíficas en base a las necesidades familiares mencionadas por las partes en conflictos y enmendar en la mayoría de los casos el lazo familiar de forma integral, la cultura jurídica pacifica busca la apertura del diálogo constructivo, cooperativo que logra arribar a soluciones creativas y justas en donde las familias tengan un acceso efectivo a la justicia alterna pero para lograr esto se requiere la influencia positiva de todos los involucrados, es decir los operadores jurídicos y las partes.

\section{La influencia de los operadores jurídicos frente a la mediación familiar}

Los operadores jurídicos tienen un importante papel en el impulso de la mediación familiar en sede judicial, ya que los abogados litigantes y los jueces familiares son los

principales responsables para persuadir a las partes a que acudan a un proceso de MASC, con ayuda de la información que brinde el juez familiar, conjuntamente con el asesoramiento de los abogados familiares sobre cómo deben las partes proceder y actuar frente a un proceso de mediación en sede judicial.

\footnotetext{
${ }^{27}$ GONZÁLEZ CARVAJAL, Jorge Isaac."CConsideraciones generales sobre la buena fe procesal y el abuso procesal”. Revista Latinoamericana de Derecho Procesal 1, No 3, mayo, México, 2015.
} 
El abogado "debe evitar todo ataque a su independencia y velar por no comprometer los valores de la profesión por complacer a su cliente, al Juez o a terceros" ${ }^{28}$, dentro de los conflictos familiares surgen emociones que nublan el objetivo real, que es llegar a una solución justa, algunas veces los clientes exigen a sus abogados hacer todo lo jurídicamente posible para evitar o ejecutar alguna determinada acción, ya sea para obtener una sentencia a favor cueste lo que cueste, o para obstaculizar los procesos para alargar la resoluciones definitivas, aquí es donde el abogado tiene la ética profesional de asesor y conducir su ejercicio profesional siempre velando por el bienestar familiar de los más vulnerables del seno familiar.

Los conflictos familiares van más allá de cuestiones pecuniarias, por lo cual la importancia de acudir a la justicia alterna con apoyo del abogado familiar, se requiere de un "profesional del derecho, libre e independiente que defiende los derechos e intereses públicos y privados mediante la aplicación de la ciencia y técnica jurídica" ${ }^{29}$ y que realmente asesore y guie a las partes que cuando el caso lo amerite persuada a su cliente a tratar de resolver el conflicto legal por medio de un proceso de mediación.

Los abogados familiares deben estar conscientes de la importancia de su función como abogado litigante en esta área, ya que se requiere que su actuar profesional no esté a los caprichos o necedades del cliente en perjuicio del seno familia "ni realizar acto alguno que estorbe la buena y expedita administración de justicia"30, el actuar del abogado familiar no debe ir encaminado a litigar un conflicto familiar por litigarlo y cumplir caprichos de las partes, la función social es brindar la mejor asesoría jurídica que le ayude al cliente a resolver la contienda legal y no permitir que las partes se envuelvany desgasten en una contienda sin fin.

"Los jueces que son las personas titulares del Poder Judicial, que ejercen la función jurisdiccional conforme a los principios de legalidad, unidad, exclusividad y

\footnotetext{
28 Universidad Nacional Autónoma de México, Código DeOntológico 14 DE LA ABogacía MeXicana Instituto de Investigaciones Jurídicas, Iniciativa para el Estado de Derecho de la Asociación de la Barra Americana de Abogados, México 2013, Fecha de consulta 27 de febrero de 2018https://archivos.juridicas.unam.mx/www/bjv/libros/7/3281/7.pdf p. 13. total de pagina 21

${ }^{29}$ DIAZ RODRÍGUEZ, Paloma. Universidad Pontificia Comillas Madrid, Facultad de Derecho. Función Social del abogado, Madrid Abril 2014, p. 2. https://repositorio.comillas.edu/xmlui/bitstream/handle/11531/541/TFG000492.pdf?sequence=1

30 Universidad Nacional Autónoma de México, Código DeOnTológico 14 DE LA ABogacía MEXICANA, Instituto de Investigaciones Jurídicas, Iniciativa para el Estado de Derecho de la Asociación de la Barra Americana de Abogados, Mexico 2013, Fecha de consulta 27 de febrero de 2018https://archivos.juridicas.unam.mx/www/bjv/libros/7/3281/7.pdf p. 15.
} 
responsabilidad"31, un juez familiar imparte y administra la justicia en el ámbito familiar velando por los derechos de cada miembro de la familia teniendo cuidado especial con el interés superior de los menores y personas en estado de vulnerabilidad,se debe concientizar a los abogados litigantes sobre la importancia de las actuaciones judiciales realizadas durante un proceso para que coadyuven a dialogar y lograr soluciones pacíficas.

Un juez de derecho familiar "ha de conocer cuál es la realidad de la familia que impera en la sociedad en la que opera." ${ }^{32}$, debe de tener conocimiento de derecho, de hecho y de la realidad social del área que juzga, para poder brindar a la sociedad decisiones judiciales efectivas, pero deben adquirir nuevas aptitudes frente al proceso judicial, en cual permita identificar qué casos son viables para brindar un efectivo acceso a la justicia alterna y con ello contribuir a combatir la resistencia al cambio en la forma de obtener justicia a las familias en conflicto.

Los jueces "han de estar atento a la realidad social e institucional necesariamente cambiante que le rodea" ${ }^{33}$. El sistema judicial se encuentra en constante cambio siempre en busca de una eficaz impartición de la justicia, y resulta necesario que los jueces se involucren de forma activa, ya que esta profesión "no puede limitarse al saber jurídico tradicional"34, la sociedad cambia, los modelos familiares cambian y en consecuencia el derecho tiene que cambiar e ir a la par de las necesidades presentes en los conflictos familiares, por lo cual las actuaciones procesales de los jueces puede influir para que las partes continúen con el proceso judicial o adquiera habilidades de persuasión hacia las partes en aquellos casos donde se considere viable la intervención de los mecanismos alternativos.

Uno de los factores que influye para que los abogados informen y asesoren a sus clientes sobre los mecanismos alternativos son el cobro del honorario, ya que los abogados perciben que se les deja fuera cuando se implementa un procedimiento de mediación, ya que el pensamiento tradicional de los abogados litiganteses que cobran solosi litigan un asunto, pero esto solo obedece a un pensamiento errado, ya que

\footnotetext{
${ }^{31}$ DIAZ RODRÍGUEZ, Paloma. Universidad pontificia Comillas Madrid, Facultad de Derecho. Función Social del abogado, Madrid Abril 2014, p. 2. https://repositorio.comillas.edu/xmlui/bitstream/handle/11531/541/TFG000492.pdf?sequence=1

${ }^{32}$ MALEM SEÑA, Jorge F;EZQUIAGA GANUZAS, F Javier;ANDRÉS IBAÑEZ, Perfecto.El error judicial. La formación de los Jueces. Fontamara, México, 2012, p.113.

${ }^{33}$ Ibid. p.p. 122 y 123.

${ }^{34}$ Ibid.p. 123.
} 
efectivamente el abogado tiene la función social de litigar y defender los derechos y exigir obligaciones durante un proceso judicial, pero no podemos descartar el hecho que hoy existe un proceso conciliador y que los abogados deben empezar a involucrarse y capacitarse y cobrar por ello, de una forma más rápida y simple que si de un proceso judicial se tratara.

Los MASC no son nuevos en nuestro ordenamiento jurídico, pero si se puede considerar de reciente aplicación en los proceso judiciales en materia familiar lo que sitúa a la justicia alterna como algo nuevo o diferente para solucionar los conflictos legales, "La innovación tiene un gran valor en el mundo actual y desde luego lo tienen en cuestiones jurídicas" 35 por lo cual esta nueva forma de resolver los conflictos familiares por medio del procedimiento de mediación, los abogados deben explorar este nuevo nicho de oportunidad que contempla el sistema judicial en México y en otras partes del mundo.

Los abogados litigantes deben adoptar nuevas funciones en su ejercicio profesional, como brindar asesoría adicional, demostrar a las autoridades judiciales y a la sociedad que su participación como abogado consultor dentro de los procesos de mediación son de gran ayuda y utilidad, aportando y generando a la sociedad soluciones efectivas en un menor tiempo y no por eso significa que conlleve un menor ingreso en el honorario, al contrario se debe valorar el trabajo del abogado como consultor dentro de los proceso de mediación por parte de los jueces familiares y de la sociedad.

Los abogados en materia familiar tienen un fuerte reto que es lograr influir por medio de sus asesorías legales para guiar a sus clientes a elegir vías de soluciones alternas haciendo ver que con ayuda del abogado litigante durante el proceso de mediación familiar existe una gran posibilidad de obtener soluciones acorde a las necesidades familiares y de forma rápida y concientizar a las partes el gran valor jurídico sobre la labor del abogado familiar para estar al frente de la asesoría legal y a su vez actuar en todo momento como un consultor legal para aconsejar de forma asertiva durante todo el proceso de mediación familiar en sede judicial.

El abogado litigante debe empezar a trabajar en un nuevo perfil de abogado como un consultor legal el cual proyecte nuevas formas de resolver el conflicto y "plantear un aumento de honorarios si logramos innovar: me refiero a la oferta de servicios

${ }^{35}$ CARBONELL, Miguel.Los Honorarios Profesionales de los Abogados. Centro de Estudios Carbonell A.C., Ciudad de México, 2017 p. 64. 
profesionales que otros despachos no tienen o un tipo de respuesta para los problemas

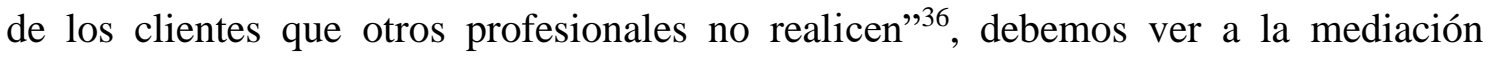
familiar en sede judicial como un nuevo nicho de oportunidad por explorar.

Los abogados litigantes deben "ser flexibles y atentos a la evolución de nuestro campo de trabajo" ${ }^{37}$ la profesión del abogado consiste estar en un constante estudio en el cual nos permita estar actualizado en las novedades judiciales y a su vez desarrollando nuevas habilidades y competencias, para no quedar como profesionales obsoletos debemos trabajar fuerte en cada cambio judicial, así como los abogados se prepararon académicamente, por medio de diplomados, cursos y talleres para hacer frente a los juicios orales, lo mismo debe aplicar para ahora conquistar una nueva área de oportunidades que son los mecanismos alternativos en especial la mediación en sede judicial.

El juez administra la justicia, aplica la justicia y "el abogado es un servidor de la justicia y un colaborador de su administración" 38 ambas figuras son importantes en el desarrollo y crecimiento de la mediación familiar en sede judicial, pero necesitamos la valoración por parte de la autoridad judicial no solo como abogados litigantes, sino también como abogados consultores o colaboradores en las mediaciones familiares en sede judicial y los abogados deben transmitir y concientizar la importancia de que las partes en conflictos acudan a un mecanismo alternativo.

Los operadores jurídicos tienen todas la facultades y capacidades necesarias para lograr influir positivamente en la voluntad de las partes, para facilitar el acceso a la justicia alterna y por otro lado los abogados participar de forma colaborativa como consultor de la justicia alterna y en la elaboración de una solución efectiva por medio de la mediación familiar en sede judicial, por lo cual se necesita trabajar en conjunto tanto los operadores jurídicos con ayuda del proceso judicial como instrumento que permita el efectivo acceso a la justicia alterna.

\footnotetext{
${ }^{36}$ CARBONELL, Miguel.Los Honorarios Profesionales de los Abogados. Centro de Estudios Carbonell A.C., Ciudad de México, 2017 p. 64.

${ }^{37}$ Ibid.p. 74.

${ }^{38}$ Universidad Nacional Autónoma de México, Instituto de Investigaciones Jurídicas, Iniciativa para el Estado de Derecho de la Asociación de la Barra Americana de Abogados, México 2013, Fecha de consulta 27 de febrero de 2018 p. 14
} 


\section{El principio de la accesibilidad procesal frente a la mediación familiar en sede judicial}

El proceso judicial es un instrumento utilizado por los abogados litigantes para resolver conflictos legales, los cuales se encuentran regulados por los códigos adjetivos mediante el cual se señalan las reglas y principios que los rigen para hacer valer algún derecho u obligación, "el proceso ha dejado de ser solo una serie de formas y ritos que se plasman en las codificaciones adjetivas estatales, para nutrirse de una serie de principios e instituciones que le dan un sentido humano de protección"39.

"El proceso sirve al derecho: es una herramienta mediante la cual se desenvuelve la jurisdicción, se aplica la ley y los particulares pueden acceder a la justicia" 40 , se requiere que por medio de los procesos judiciales se permita una eficaz desarrollo del proceso de mediación en base a principios, reglas y valores con la finalidad de que las partes obtengan por medio del proceso judicial un efectivo acceso a la justicia, "la finalidad ideal que debe perseguir el proceso jurisdiccional es la de solucionar controversias para lograr el equilibrio, la paz y la tranquilidad sociales" 41 , los procesos judiciales sirven para llegar a una sentencia y poder hacer valer los derechos y obligaciones de las partes. Los procesos judiciales son lo que se desarrollan en el ámbito judicial y los procesos alternos son aquellos que se desarrollan en el ámbito de la justicia alterna por medio de los mecanismos alternativos, en los procesos judiciales las partes litigan y por medio de las pruebas las partes tratan de demostrar ante el juez la verdad legal lo cual permite obtener una sentencia judicial, en cambio los procesos alternos permiten desarrollar y trabajar desde el lado de las necesidades e intereses de las partes sin buscar durante el proceso cual parte tiene la razón en un determinado conflicto familiar gestionando el conflicto y procurar transformarlo, los dos procesos buscan un orden social.

El sistema judicial debe permita adquirir métodos y estrategias judiciales que rompan con la apatía social que impida obtener un acceso a la justicia alterna donde pueda obtener una solución a su conflicto más ad-hoc, que permita la integración familiar en base a los interese familiares de forma voluntaria, logrando un equilibro social, a través

\footnotetext{
${ }^{39}$ SALINA GARZA, Juan Àngel.Tutela Judicial Efectiva, Una Visión Constitucional de la teoría del proceso.Novum, México, 2016, p.13.

${ }^{40}$ Ibid. p.27

${ }^{41}$ GÓMEZ FRODE, Corina. Manual de Teoría General del Proceso. Tirant lo Blanch. México, 2017, p. 17.
} 
del dialogo entre sus miembros, lo cual es la base de la sociedad, buscando que la sociedad empiece adoptar nuevas formas de resolver los conflictos familiares en el ámbito legal en base a valores y principios.

Todos los procesos está regido por principios procesales la cual comprende ciertas reglas que van encaminadas a darle fuerza al sistema judicial, uno de los principios procesales que menciona, es el acceso a la justicia el cual dice que "un cumulo de obstáculos lo impide o al menos lo reduce: el acto costo del patrocinio, la onerosidad de la administración de justicia, el burocratismo, la extrema complejidad de los procedimientos, la lentitud"42, el efectivo acceso a la justicia se obtiene aplicando principios que ayuden a eliminar la burocracia, y la extrema complejidad de los procedimientos y logrando aumentar el acceso a la justicia hacia las partes dentro de los juicios familiares.

"El proceso cómo método debe seguir pautas no sólo formales (normas procedimentales) sino que regulen, al menos implícitamente, la actitud ética de sus intervinientes, de ahí que surge el problema de trazar límites a esos imperativos y más concretamente de la conducta específica que debe exigirse a los sujetos procesales sobre la base de estas normas" 43 de modo que al referirme al principio procesal de accesibilidad procesal, se hace alusión al acceso efectivo a la justicia alterna dentro de los juicios familiares.

Elacceso a la justicia es un derecho fundamental de los gobernados que consiste en la posibilidad de ser parte en un proceso para exigir un derecho, pero este derecho humano, va más allá de acudir solo ante una autoridad judicial o administrativa, pues a partir de las reformas al artículo 17 constitucional "se establecieron que una de las formas de resolver controversias entre gobernados es mediante el ejercicio de los mecanismos alternativos de solución de controversias"44, en la cual sostuvieron en la parte que interesa al caso que los preceptos 17 de la Carta Magna, 8 de la Convención Americana de Derechos Humanos y 14 del Pacto Internacional de Derechos Civiles y Políticos,“...establecen el derecho humano a la solución de conflictos, ya sea mediante

\footnotetext{
${ }^{42}$ FAIREN GUILLÉN, Víctor.Teoría General del Derecho Procesal. Universidad Nacional Autónoma de México Instituto de Investigaciones Jurídicas. México, 1992, p. LXI.

${ }^{43}$ GONZÁLEZ CARVAJAL, Jorge Isaac."Consideraciones generales sobre la buena fe procesal y el abuso procesal".Revista Latinoamericana de Derecho Procesal 1, N 3, México, mayo 2015. p.p 13 y 14. ${ }^{44}$ Magistrado del segundo tribunal colegiado en materia civil del tercer circuito, en sentencia de amparo en revisión 278/2012,de 13 se septiembre 2012. p.138.
} 
el acceso efectivo a la tutela judicial o mediante los mecanismos alternativos de solución de controversias..."45

De lo anterior se advierte que el acceso a la justicia alterna se encuentra en un mismo plano jurídico, que el acceso a la jurisdicción, o tutela judicial efectiva que "es un derecho humano de trascendental importancia, pues de él depende en gran medida la realización plena del estado de derecho"46, y se deben percibir de forma equiparable, esto cobra sustento con el siguiente criterio:acceso a los mecanismos alternativos de solución de controversias, como derecho humano. goza de la misma dignidad que el acceso a la jurisdicción del estado, el cual reconoce como derecho humano el resolver los conflictos por medio de los mecanismos alternativos de solución de controversias, "ante tal contexto normativo, debe concluirse que tanto la tutela judicial como los mecanismos alternos de solución de controversias, se establecen en un mismo plano constitucional y con la misma dignidad y tienen como objeto, idéntica finalidad (...)"47. De lo anterior, se advierte que el derecho humano a la solución de conflictos se encuentra estrechamente relacionada con el acceso a la justicia que va mas haya de acudir a tribunales judiciales o administrativos, pues dicho derecho se ciñe también a los métodos alternos para la solución de conflictos, de modo que el acceso a la justicia tiene dos vías la tradicional y la alterna.

\section{REFERENCIAS}

BISQUERRA ALZINA, Rafael Cuestiones sobre bienestar. Editorial Síntesis.España, 2013.

CARBONELL, Miguel. Los Honorarios Profesionales de los Abogados, (Ciudad de México, Editorial Centro de Estudios Carbonell A.C.), México, 2017.

DIAZ RODRÍGUEZ, Paloma. "Función Social del abogado". Disponible en: https://repositorio.comillas.edu/xmlui/bitstream/handle/11531/541/TFG000492.pdf? sequence $=1$. visitado el 10/01/2018.

\footnotetext{
${ }^{45}$ Ibid. p. 153 .

${ }^{46}$ SALINA GARZA, Juan Àngel.Tutela Judicial Efectiva, Una Visión Constitucional de la teoría del proceso.Novum, México, 2016, p.11

47 Tribunales Colegiados de Circuito, Semanario Judicial de la Federación y su Gaceta, Registro: 2004630, octubre de 2013, p. 1723.
} 
FAIREN GUILlÉN, V. Teoría General del Derecho Procesa (primera ed.). México: Universisas Nacional Autónoma de México Instituto de Investigaciones Juridicas. México, 1992.

GARCIA VILLALUENGA, L. La mediacion familiar: una aproximacion normativa. Revista del Instituto de Ciencias Juridicas(20), 78-96. Obtenido de http://www.redalyc.org/pdf/2932/293222932005.pdf. México, 2007.

GARCÍATREVIÑO, Ricardo. Los Contratos Civiles y sus Generalidades ( $6^{\circ} \mathrm{ed}$.). Mc Graw-Hill Interamericana Editores S.A. de C.V. México, 2002.

GONZÁLEZ CARVAJAL, J. I. (Mayo de 2015). "Consideraciones generales sobre la buena fe procesal y el abuso procesal". Revista Latinoamericana de Derecho Procesal(3), 27. Recuperado el 26 de febrero de 2018, de https://www.academia.edu/35836939/Buena_fe_procesal_y_abuso_procesal?auto=d ownload\&campaign=weekly_digest

GÓMEZ FRODE, Corina. Manual de Teoría General del Proceso. Editorial Tirant lo Blanch. México, 2017.

GORJÓN GÓMEZ, F. J. Métodos Alternos de Solución de Controversias.Editorial Continental. México, 2007.

GORJÓN GÓMEZ, Francisco Javier. Mediación su valor intangible y efectos operativos. Una visión integradora de los MASC. Editorial Tirant Lo Blanch. México, 2017.

MALEM SEÑA, Jorge F, Ezquiaga Ganuzas, F Javier y AndrésIbañez, Perfecto. El error judicial. La formación de los Jueces (Madrid-México Editorial Fundación Coloquio Jurídico Europeo, Madrid, España y Distribuciones Fontamara S.A.), pp. 157. ISBN 978-607-7971-93-1. 2012.

MEMBIElA POLLÁN, Matías. Teoría del capital social. Editorial Camiño Do Faro. España, 2016.

PAStRAnA AGUIRRE, L. A. La mediacion en el Sistema Procesal Acusatorio en Mexico. Flores Editor y Distribuidor S.A. de C.V. México, 2009.

PEÑA GONZÁLEZ, O. Mediación y Conciliación Extrajudicial. Medios Alternos de Solucion de Conflictos. Teoría y Práctica. Flores Editor y Distribuidor, S.A. de C.V. México, 2010.

REDORTA, Josep. Como sobrevivir a la sociedad del malestar y el conflicto. Editorial Almuzara. España, 2018. 
SALINA GARZA, Juan Àngel. Tutela Judicial Efectiva, Una Visión Constitucional de la teoría del proceso. Editorial Novum.México, 2016.

Suprema Corte de Justicia de la Nación. Anuario de la Cultura Juridica Mexicana. México, Distrtio Federal: Suprema Corte de justicia de la Nación. Obtenido de https://www.scjn.gob.mx/sites/default/files/publicaciones_scjn/publicacion/201703/67860.pdf

TORRES BUENROSTRO, E.. "Cultura, Cultura Juridica y Enseñanza del Derecho: Factores Trascendentales de cambio social". Biblioteca Juridica Virtual del Instituto de Investigaciones juridcas de la UNAM, 32. Obtenido de https://revistas-

colaboracion.juridicas.unam.mx/index.php/sufragio/article/view/22193/19787y Valencia, M. Z. (2016). Contratos Civiles ( ${ }^{\circ}$ ed.). México: Porrúa S.A. de C.V 